\title{
Estado de Exceção Permanente: 0 campo e a experiência biopolítica
}

\section{Permanent State of Exception: the camp and the biopolitics experience}

\author{
Lucas Moraes Martins \\ Centro Universitário UNA, Belo Horizonte - MG, Brasil \\ Universidade FUMEC, Belo Horizonte - MG, Brasil
}

\begin{abstract}
Resumo: O presente artigo pretende apresentar, concisamente, o conceito de campo e como ele foi um absoluto espaço biopolítico. A relação entre o estado de exceção permanente (o campo) e a biopolítica foi apresentada a partir da obra de Giorgio Agamben. Concluiu-se que o campo foi um absoluto espaço biopolítico, porque, nele, as cesuras biopolíticas não recaíam sobre a zoé politizada, mas sobre a vida nua que não podia mais ser inscrita no ordenamento jurídico. Entendendo a estrutura do campo, pode-se fortalecer a nossa luta contra os espaços de exceção existentes dentro das atuais democracias.
\end{abstract}

Palavras-chave: Campo. Biopolítica. Giorgio Agamben.

\begin{abstract}
This article concisely presents the concept of camp and how this was an absolute biopolitical space. The relationship between the permanent state of exception (the camp) and biopolitics was presented from the work of Giorgio Agamben. It was concluded that the camp was an absolute biopolitical space, because in this space, the biopolitics caesuras didn't affect the politicized zoé, but upon the bare life that couldn't be anymore included in the legal system. Understanding the structure of the camp, we can strengthen our fight against the existing spaces of exception in the democracies.
\end{abstract}

Keywords: Camp. Biopolitics. Giorgio Agamben. 


\section{Introdução}

O campo é o paradigma do espaço político moderno, o ponto onde política transforma-se em biopolítica e o homo sacer, o portador da vida nua, se torna indistinguível em uma zona cinzenta (AGAMBEN, 2000).

Para se compreender de forma adequada a atualidade política desta afirmativa de Giorgio Agamben, por vezes mal compreendido, é necessário entender o funcionamento do estado de exceção. Este, em sua forma arquetípica, é essencialmente caracterizado por uma suspensão temporária do ordenamento jurídico, por força de uma decisão soberana. Entretanto, quando se procurou dar uma localização territorial permanente ao estado de exceção, surgiu o campo, a exceção feita regra.

Entendendo o funcionamento singular do campo e sua estreita relação com a experiência biopolítica, pode-se trazer a lume os espaços de exceção dentro das democracias. Não se trata, portanto, de procurar apenas por um espaço de confinamento cercado por arames farpados, mas de investigar em quais espaços a norma e a vida nua entram em uma zona cinzenta de indistinção.

O tema contém uma pertinência política atual, notadamente quando se percebe que a teoria do estado de exceção "[...] não pode ser um fim ou um objetivo em si mesmo, senão que tem que estar inscrita em um conjunto mais amplo, no contexto das tecnologias de governo" (AGAMBEN, 2014, p. 3). A política ocidental moderna tem demonstrado a crescente coincidência entre os paradigmas do governo e do estado de exceção através de uma "[...] prática gerencial que governa o curso das coisas, adaptando-se cada vez, em seu intento salvífico, à natureza da situação concreta com que deve medir forças" (AGAMBEN, 2011, p. 64). Não se trata de uma quimera. $\mathrm{O}$ estado de exceção permanente como paradigma gerencial tem sido amplamente utilizado, por exemplo, no âmbito econômico, como uma medida diante de situações urgentes em favor do poder financeiro desatrelado das funções estatais (BERCOVICI, 2008). Todavia, em um viés mais benjaminiano, questiona-se precisamente o papel estatal dentro das relações éticas e políticas, porquanto a biopolítica não 
surge com capital, mas com a fundação do Estado. Por isso, afirmar que o “[...] catastrofismo agambeniano é mobilizado no âmbito de um rígido determinismo do capital [...]" (COCO, 2009, p. 121) ou que, para Agamben, quem decidiria sobre a validade da regra ou da exceção seria determinantemente o capital, implica ter entendido mal os desdobramentos do projeto Homo Sacer. Não que Agamben não critique o capitalismo, mas, superando a lógica binária imposta pelas dicotomias, o Estado surge, também, como fator problemático em relação "[...] à pergunta que não pára de ressoar na história da política ocidental: o que significa agir politicamente?" (AGAMBEN, 2007, p. 12). Pergunta muito próxima ao problema exposto por Benjamin (1999), logo no início do texto Zur Kritik der Gewalt, sobre a violência (Gewalt) e relação desta com o direito e a justiça.

Sabe-se que Pasolini (2012, p. 98-109) havia questionado a legalização do aborto com receio de que o aborto e a vida fossem relegados e administrados pelo capital e, nesse ponto, há claramente um vislumbre do perigo do mercado se apropriar dos corpos por meio de uma espécie de biopolítica. Todavia, o fortalecimento do Estado, sob o crivo da soberania popular, apenas retomaria toda a teia construída em torno da vida nua, aquela exposta constantemente à violência soberana e às técnicas de administração dos corpos, reforçando, portanto, a biopolítica.

Diante da atualidade e da urgência deste quadro, deve-se perguntar como surge e opera o estado de exceção permanente e como este se relaciona com a biopolítica. Entretanto, para se entender como surge o campo, torna-se necessário revisitar, inicialmente e brevemente, a obra Teologia Política de Carl Schmitt.

\section{O Estado de Exceção em Carl Schmitt}

Em Teologia Política, Carl Schmitt faz uma verdadeira apologia da exceção, ligando-a diretamente à figura do soberano. "Soberano é quem decide sobre a exceção" (SCHMITT, 2004b, p. 13)1. Esse pensamento de Schmitt pressupõe que as relações da vida e, principalmente, a política, não se adequam integralmente à norma jurídica. Para Schmitt, o contínuo

1 No original: "Souverän ist, wer über den Ausnahmezustand entscheidet." 
funcionamento normal do ordenamento jurídico - mecanismo entorpecido pela burocratização impessoal e pela repetição engendrada pelo modelo de norma jurídica universalmente válida para todas as situações - é interrompido pela irrupção da vida, pela situação de exceção.

Ocorre que, para Schmitt, as ações e os motivos políticos seriam sempre estabelecidos na distinção amigo/inimigo, uma diferenciação que não usa de categorias morais, estéticas ou econômicas. O inimigo é o outro, o estranho, o existencialmente diferente e tal classificação imprecisa basta para qualificá-lo (SCHMITT, 1996). O inimigo, que a princípio não deveria ser eliminado, mas neutralizado, é o fator que confere identidade política.

A zona cinzenta na qual a figura do inimigo esta imersa é essencial e nunca poderá deixar de existir, porque ela engendra o conflito político e, sem este, não há política para Schmitt (1996). Por outro lado, se os conflitos podem sempre aparecer, a própria indeterminação do inimigo implica que tais contingências não podem ser capturadas por uma norma geral (SCHMITT, 2004b). Alguém precisa decidir, genuinamente e politicamente, quem é o inimigo e quando surge uma situação conflituosa. Entretanto, se a vida humana e a relação política não podem ser reduzidas à norma, o direito não está apto a identificar o inimigo e determinar a situação fática geradora da anormalidade, do momento crítico para o Estado. Portanto, como tal decisão não poderia advir exclusivamente da norma, caberia ao soberano o fardo da decisão, pois muito embora esteja dentro do ordenamento jurídico, também se encontra fora, justamente para que seja possível a tomada de decisões delimitando o inimigo e, assim, garantindo as relações políticas. O soberano está dentro do ordenamento jurídico porque garante a ancoragem do estado de exceção no ordenamento jurídico (AGAMBEN, 2004), mas também deve estar fora para que possa decidir sobre a exceção.

O milagre da exceção surge exatamente nesse ponto. Para Schmitt, essa ambiguidade do soberano - aquele que está dentro e fora da ordem jurídica - é extremamente necessária. Se o soberano se circunscrevesse exclusivamente à ordem jurídica, não poderia decidir sobre a exceção, já que esta não pode ser prevista pelo direito positivo e a decisão "soberana" 
ficaria restringida ao âmbito interno do ordenamento jurídico. Seria como uma tentativa de realizar um milagre seguindo às leis naturais já dispostas no mundo físico. Portanto, apesar de fazer parte do ordenamento jurídico, o soberano deve também estar fora dele, se libertando de qualquer restrição advinda do direito para que, decidindo sobre a exceção, realize o milagre - estado de exceção - assegurador das relações normais da vida. Logo, o soberano atua à semelhança de Deus, já que o milagre somente pode ser entendido se houver uma suspensão das leis naturais com a consequente divina interferência direta no mundo.

Mesmo que Schmitt não tenha criado uma verdadeira teoria da soberania, a proposição schmittiana de que a norma vive da exceção - ou, dito de outro modo, que a exceção vivifica a norma - deve ser levada a sério. A questão essencial para Schmitt foi a de estabelecer uma proximidade imediata, um ponto de convergência entre ordem factual e ordenamento jurídico. Schmitt não está preocupado em desenvolver uma teoria da soberania, mas sim em construir um "[...] fundamento concreto de uma ordem normativa abstrata” (FERREIRA, 2004, p. 105).

Schmitt (2004b) estava ciente de que a norma, como pura forma de lei e, portanto, com pretensões à universalidade, não continha, em si mesma, a própria eficácia. Se "todo direito é direito situacional" (SCHMITT, 2004b, p. 19)2 , isso demonstra a radical separação entre situação fática e norma, vida e direito. Em outras palavras, se a norma não contém a própria eficácia, mas precisa de um elemento externo factual, seria necessário estabelecer a normalidade fática, antes de qualquer aplicação da norma. Schmitt pôde chegar a esta conclusão somente por seu olhar estar voltado para a anormalidade, ou seja, para caso-limite. Se a norma pode ser aplicada cotidianamente é porque as situações da vida se repetem, mas, diante da anormalidade, a realidade fática demonstra que não pode ser subsumida à norma e que as condições de eficácia do ordenamento jurídico não se encontram em si mesmo. Por isso, a decisão soberana é importante, pois se a norma somente se aplica ao caso normal e o caos, obviamente, é uma anormalidade, o direito não poderia ser aplicado a essa vida desordenada e, portanto, a máquina jurídica estaria emperrada.

2 No original: "Alles Recht ist "situationsrecht"”. 
Entretanto, se existe alguém, o soberano, que realiza a articulação entre anormalidade e ordenamento jurídico, que tem o poder de criar a situação de normalidade, o direito está a salvo, nem que para isso tenha que ser suspenso. Daí, é possível concluir que, em última instância, o ordenamento jurídico funciona ancorado no estado de exceção, ou melhor, vive da exceção e é constantemente confirmado por esta.

Dentro desse contexto, a decisão soberana se revela absolutamente independente da norma. Uma fratura insuperável. Ao suspender a norma e estabelecer a situação de normalidade fática pressuposta para a instituição do ordenamento jurídico, fica demonstrado que a decisão surge do nada normativo. Assim, como Deus criou o mundo do nada, a decisão soberana também emana do nada, sendo suficiente a presença do seu elemento personalista, encarnado na figura do soberano.

Isso é importante, pois à afirmação de Schmitt, de que soberano é quem decide sobre (über) a exceção, subjaz um duplo sentido justamente na palavra über: como as situações excepcionais não podem ser codificadas, a decisão sobre a exceção tem a força de constituí-la. Não se trata de uma mera declaração de algo pré-existente, pois uma situação somente será excepcional porque o soberano a nomeou assim. O soberano tem a palavra viva, aquela que cria o que nomeia. Todavia, decidir sobre a exceção implica também as atitudes a tomar diante da anormalidade, isto é, o que deve ser feito para criar a normalidade novamente. Em suma, a decisão soberana constitui a exceção e, ao mesmo tempo, estabelece quais são as condições fáticas normais que devem reinar, para que a norma jurídica possa voltar a ser aplicada.

Esse é um dos principais pontos de Agamben nos livros Homo $\mathrm{Sa}$ cer: o poder soberano e a vida nua I e Estado de exceção. Agamben parte da noção schmittiana de soberania como conceito-limite e da evidência de que a norma, como pura forma de lei e, portanto, com pretensões à universalidade, para fazer referência ao real, pressupõe uma relação com o que lhe é exterior, isto é, com o próprio real, com os fatos, com a vida. Entretanto, Agamben introduz uma variante peculiar ao interpretar a relação entre exceção e norma, já descortinada por Schmitt. 
O estado de exceção pressupõe a existência de uma decisão soberana que tenha suspendido a norma para tornar possível a normatização da vida, para garantir a estruturação normal das relações de vida, conforme indicado por Schmitt em Teologia Política, porquanto a norma não pode ser aplicada à anormalidade. Entretanto, ao decidir sobre a exceção, com a consequente suspensão da norma - e aqui está uma das variantes essenciais - Agamben sugere o surgimento de algo "[...] que concerne à natureza mais íntima da lei” (AGAMBEN, 2010a, p. 32): a relação de exceção como aquela que "[...] exprime a estrutura originária da relação jurídica" (AGAMBEN, 2010a, p. 26).

A relação de exceção não se reduz a disposição topológica entre norma e exceção a uma simples exclusão - ou/ou (Ou a norma se aplica, excluindo a exceção; ou a exceção se aplica, excluindo a norma): o excluído, imediatamente, é incluído, em virtude da própria exclusão. A exceção não habitaria simplesmente a exterioridade da norma sem qualquer relação com esta. Para Agamben (2010a, p. 24), a "[...] norma se aplica à exceção desaplicando-se [...]" e isso implica que a norma mantém uma relação com a exceção na forma de sua suspensão, isto é, o estado de exceção surge como uma situação resultante da suspensão da norma. O soberano, por conseguinte, pode decidir sobre a estruturação das relações normais da vida de que a lei necessita para ter referência na vida real.

Entretanto, se a normalização da vida através da decisão soberana é possível porque a suspensão temporária do ordenamento jurídico cria uma zona de indistinção entre fato (factum) e direito (ius) (AGAMBEN, 2010a), Schmitt nunca aceitou que regra se confundisse com exceção. O que existiria seriam períodos de normalidade e períodos de exceção.

Em Schmitt, como o estado de exceção não se confunde com a regra e, além disso, pode surgir a qualquer momento em virtude de uma decisão soberana, este estado não tem uma localização fixa no território. O estado de exceção, teorizado por Schmitt, caracterizado pela suspensão temporária do ordenamento jurídico, é um ilocalizável, um ordenamento sem localização. Pode-se, portanto, para fins deste artigo, denominar o estado de exceção teorizado por Schmitt de "estado de exceção temporário", pois, quando "[...] nosso tempo procurou dar uma localização 
visível permanente a este ilocalizável, o resultado foi o campo de concentração" (AGAMBEN, 2010a, p. 26). Quando o estado de exceção se confunde com a regra e tende a permanecer no tempo, surge o campo, o "estado de exceção desejado" ou permanente, o espaço absoluto de exceção (AGAMBEN, 2010a, p. 26).

\section{A Biopolítica e o Poder Soberano}

O campo é a materialização do estado de exceção. A diferença crucial entre estado de exceção temporário e estado de exceção desejado ( campo) é que o último se desprende da situação que enseja a suspensão temporária do ordenamento, fazendo com que a situação de exceção transforme-se em situação normal, isto é, que o estado de exceção vigore como situação normal. Ao se dar uma localização territorial ao estado de exceção (campo) e na medida em que isso é "desejado", cria-se, portanto, um lugar permanente onde norma e fato tornam-se indiscerníveis. Ao "desejo" de criar o campo, corresponde o "desejo" de se criar uma zona localizável de indistinção entre norma e fato, isto é, o soberano realiza permanentemente o estado de exceção ao instaurar no território um estado de exceção desejado (AGAMBEN, 2010a, p. 164).

O campo é um território fora do ordenamento jurídico. Entretanto, se o campo é a parte do território colocado para fora do ordenamento jurídico e toda exclusão sempre é inclusiva, o que o ordenamento jurídico captura, ao excluir o campo de si, é o próprio estado de exceção na sua forma permanente. Eis, portanto, como o ilocalizável juridicamente (estado de exceção) torna-se localizável (campo) (AGAMBEN, 2010a; AGAMBEN, 2000).

Dessa forma, com uma localização, o estado de exceção é realizado normalmente, e não apenas excepcionalmente como acontecia com a suspensão temporária do ordenamento jurídico em situações anormais.

Portanto, o campo é a criação proposital da situação de exceção, confinando-a a um pedaço do território. Aquilo que era fruto de uma suspensão temporária do ordenamento transforma-se dentro do campo em uma nova disposição espacial estável e, justamente por isso, os habitantes 
do campo estão submetidos a uma experiência biopolítica absoluta. Dito em outros termos, o campo é também o “[...] mais absoluto espaço biopolítico [...] jamais [...] realizado, no qual o poder não tem diante de si senão a pura vida sem qualquer mediação" (AGAMBEN, 2010a, p. 167).

Se o "[...] campo é um híbrido de direito e de fato, no qual os dois termos tornaram-se indiscerníveis" (AGAMBEN, 2010a, p. 166), então seus habitantes estão totalmente expostos, continuamente, ao poder soberano que pode, a todo instante, decidir normalmente sobre o valor ou o não valor da vida.

Entretanto, caberia perguntar como Agamben pode afirmar que o campo, o estado de exceção permanente, foi o mais absoluto espaço biopolítico, porquanto, diante do trabalho de Michel Foucault, o nascimento moderno da biopolítica marcaria a decadência do poder soberano.

Conforme Foucault, o poder soberano, na figura da soberania territorial - exercida sobre a terra, sobre os produtos da terra -, era fundamentalmente um direito de vida e de morte, a "velha potência da morte" (FOUCAULT, 1999, p. 131). Segundo Foucault (2005, p. 41), esse poder, que remonta às monarquias feudais, no período da Alta Idade Média, e se estende até fins do século XVII, se expressava fundamentalmente pelo direito de fazer morrer ou deixar viver. Foucault demonstrou que na lógica do poder soberano territorial, cujo centro residia na relação soberano-súditos, focado na apropriação dos bens e produtos da terra - e nem tanto no corpo, tempo e trabalho (FOUCAULT, 2005, p. 43; FOUCAULT, 2008, p. 3-17) -, a garantia de obediência se estruturaria sobre um poder de fazer morrer ou deixar viver. Isso significa que o "[...] poder soberano sobre a vida só se exerce a partir do momento em que o soberano pode matar [...]" (FOUCAULT, 2005, p. 186-187); porque pode matar, porque pode fazer morrer, é que o soberano poderá, ao não matar, ao não fazer morrer, deixar o súdito viver.

Ainda de acordo com Foucault (FOUCAULT, 2005; FOUCAULT, 2008; FOUCAULT, 2009) a partir dos fins do século XVII e visivelmente no século XVIII, o poder soberano começa a ser recoberto por uma biopolítica, um poder que prima pela administração dos corpos e pela gestão da vida (FOUCAULT, 1999; FOUCAULT, 2005). No fim do século 
XVII, esse novo poder se centrou no corpo como máquina, disciplinando-o, adestrando-o, extorquindo sua força, docilizando-o (FOUCAULT, 1999). No século XVIII, a biopolítica desenvolveu-se em uma segunda forma, estruturada sobre os processos biológicos, vitais. A “[...] proliferação, os nascimentos e a mortalidade, o nível de saúde, a duração da vida, a longevidade [...]" (FOUCAULT, 1999, p. 131) são exemplos de processos biológicos assumidos mediante controles reguladores. Se o século XVII presenciou o surgimento das disciplinas do corpo (anátomo-política do corpo humano), o século XVIII viu surgir uma série de intervenções e controles reguladores (biopolítica da população). "As disciplinas do corpo e as regulações da população constituem os dois pólos em torno dos quais se desenvolveu a organização do poder sobre a vida" (FOUCAULT, 1999, p. 131).

Essa biopolítica, diferentemente do poder soberano, caracteriza-se não pelo fazer morrer ou deixar viver, mas pelo deixar morrer e fazer viver (FOUCAULT, 1999; FOUCAULT, 2005). A biopolítica vai estabelecer toda uma rede de disciplinas e regulamentações, normalizações, para administrar e gerir a vida orgânica do homem.

Obviamente, não se pretende esgotar a análise de Foucault sobre o poder soberano e a biopolítica neste pequeno trecho, mas é o suficiente para trazer a este artigo três pontos fundamentais que se encontram entrelaçados.

O primeiro ponto trata da bio-história. Essa noção de bio-história indica que a vida orgânica submetida pela biopolítica se encontra em um campo de forças do qual a própria vida surge como um produto constantemente remodelado pelas técnicas de poder e de saber (FOUCAULT, 1999). Ao mesmo tempo em que a biopolítica decompõe e compõe a vida, ela influencia e altera as técnicas de poder. Vida e política estão em um campo de permanente tensão entre si (ESPOSITO, 2010). Assim, quando os movimentos da vida e os processos da história interferem um no outro, como disse Foucault, a vida surge pela incidência das técnicas de saber e do poder, e se torna simultaneamente um produto constantemente manipulado (ESPOSITO, 2010). 
Nesse limiar entre natureza e história, a vida orgânica não é mais um dado pressuposto da natureza, ou mesmo histórico, mas sim algo que está sendo constantemente posto em uma pugna, um “[...] produto de uma série de causas, de forças, de tensões que daí resultam modificadas também elas num jogo imparável de acções e reacções, de avanços e resistências" (ESPOSITO, 2010, p. 53). A vida não está naturalmente pressuposta, como se fosse um pilar imóvel, sobre a qual as ações políticas que buscam submetê-la construiriam toda uma técnica e um saber, mas, ao contrário, se encontra em uma permanente deslocação e arranjo. A biopolítica se coloca, portanto, como um mecanismo produtivo (ESPOSITO, 2010), cujo efeito se bifurca em duas direções: produz a subjetivação e a morte, isto é, ou uma ou outra. "Ou a biopolítica produz subjectividade ou produz morte. Ou torna o sujeito o seu objecto ou objectiviza definitivamente" (ESPOSITO, 2010, p. 55).

O segundo ponto a ser registrado se entrelaça com o primeiro. Para Foucault, o que está em cena nesta intricada rede é a vida como processo vital, ou seja, a vida natural. Para Foucault, a vida orgânica ou natural tomou o lugar central na política, pois a biopolítica se desenvolveria como uma série de intervenções e controles reguladores dos processos vitais, naturais da vida - verbi gratia, "[...] a proliferação, os nascimentos e a mortalidade, o nível de saúde, a duração da vida, a longevidade [...]" (FOUCAULT, 1999, p. 131) - ou melhor, a biopolítica incidiria crescentemente sobre quaisquer condições que pudessem fazer variar a vida como processo orgânico, vital, natural.

Há ainda um terceiro ponto, que surge como corolário desses dois últimos. Para Foucault, existiria certa ruptura ou uma descontinuidade entre poder soberano e biopolítica. Isso não significa que Foucault desconhecesse que ambos os poderes poderiam se entrelaçar e, em determinados casos, integrarem-se mutuamente (AGAMBEN, 2010b; ESPOSITO, 2010, p. 89). Entretanto, em Foucault, na modernidade - mais visivelmente no século XVIII -, a passagem do "Estado-território" para o "Estado-população" marca o "nascimento" da biopolítica. Isso implica que, diante do novo regime biopolítico de "deixar morrer e fazer viver", o velho "direito de espada", o poder soberano de "fazer morrer e deixar viver”, se não resulta em uma simples máscara formal da biopolítica, é, 
pelo menos, recoberto e trespassado por uma nova forma de poder (ESPOSITO, 2010).

Se assim for, a afirmativa de Agamben segundo a qual a biopolítica é "[...] pelo menos tão antiga quanto a exceção soberana [...]" (AGAMBEN, 2010a, p. 14), se reveste de estranheza. Agamben (2010a), todavia, é firme na proposição pela qual a produção de um corpo biopolítico é contribuição original do poder soberano e, este ponto, merece uma explicação mais detalhada.

\section{O Campo}

O ponto-chave para se entender a proposição de Agamben, segundo a qual biopolítica é tão antiga quanto a exceção soberana, isto é, a íntima e antiquíssima relação entre poder soberano e biopolítica, passa pelo conceito de vida nua.

Agamben (2010a) relata que os gregos do mundo clássico não possuíam um termo único para designar a palavra vida, valendo-se de dois termos: zoé e bíos. O primeiro exprimia o simples fato de viver, comum a todos os seres vivos, sejam eles deuses, homens ou animais; o segundo indicava a forma de viver própria de um grupo ou de um indivíduo. Enquanto zoé designava, portanto, a vida, animal ou orgânica, bios indicava a vida qualificada de cidadão, a vida politicamente qualificada.

Com a fundação da Cidade ou Estado, ocorreu uma exclusão inclusiva da zoé na pólis. Isso significa que ao se tentar excluir a zoé (vida natural, orgânica, animal, vitae lupus) do âmbito político, acabou-se por politizá-la. Entretanto, a inclusão da zoé na Cidade, ou melhor, a politização da vida natural, acabou por produzir a vida nua, aquela virtualmente matável. Excluiu-se a zoé e, automaticamente, produziu-se vida nua no interior da pólis, como princípio jurídico-político originário. Dito de outro modo, excluiu-se a violência de todos contra todos (homo hominis lupus) do estado de natureza (zoé) e, consequentemente, acabou-se por incluir essa mesma violência na figura da violência soberana (ius contra omnes), à qual todos os portadores da vida nua estão permanentemente expostos pelo poder soberano. 
Uma vez que a fundação da cidade ou Estado não é "[...] um evento que se cumpre de uma vez por todas in illo tempore, mas é continuamente operante no estado civil na forma de decisão soberana [...]" (AGAMBEN, 2010, p. 108), a pólis foi e continua sendo estruturada sobre a relação de exceção. A própria exceção, assim como a vida nua, é, por conseguinte, tão antiga quanto o poder soberano. Para Agamben, a vida nua é um produto da lógica da soberania, da exceção soberana.

Enfim, como a vida nua está desde sempre interligada ao poder que a subjuga, Agamben pode afirmar que colocando a vida biológica (zoé) “[...] no centro de seus cálculos, o Estado moderno não faz mais, portanto, do que reconduzir à luz o vínculo secreto que une poder à vida nua [...]" (AGAMBEN, 2010a, p. 14). Logo, a biopolítica não nasce na modernidade, conforme as lições de Foucault, mas se encontra no âmago da própria relação de exceção, que exprime a estrutura originária da relação jurídica-política ocidental, já que desta surge a vida nua.

Como consequência e a despeito de partir parcialmente de Foucault, Agamben pode discordar deste em três pontos: primeiro, se a vida nua é tão antiga quanto o poder soberano, o "nascimento moderno" da biopolítica não marca a decadência do poder soberano, mas apenas demonstra uma contiguidade entre estes poderes. Em segundo lugar, não é a vida natural que foi submetida às técnicas e regulações biopolíticas, como imaginava Foucault, mas a vida nua.

Como consequência destes dois últimos pontos, Agamben sustenta que o marco da biopolítica moderna é o estado de exceção feito campo, ou seja, o campo como o "nómos do moderno" (AGAMBEN, 2010a, p. 162).

Falar em campo como nómos do moderno significa dizer que aquele se erigiu em matriz oculta da política da modernidade. Quando o estado de exceção emerge em primeiro plano e tende a se tornar a regra, o estado de exceção desejado, é criada uma zona territorial de permanente indistinção entre fato e norma, na qual a redução das pessoas à vida nua torna-se visível ao extremo. 
Originalmente, as cesuras biopolíticas foram feitas pela mediação do nascimento-nação. Em outras palavras, a regra automática, por exemplo, de que alguém se torna parte da nação (cidadão) por meio do nascimento, era o mecanismo responsável por inscrever a vida nua no sistema político. O que significa, então, que a biopolítica era mediada por regras automáticas de inscrição da vida no corpo político. O cidadão fazia parte do corpo político (Estado) e de uma localização (território) através de regras automáticas de politização da vida natural (zoé), por exemplo, o nascimento fazia automaticamente da pessoa um cidadão, inscrito na pólis como vida nua (AGAMBEN, 2010a).

Entretanto, afirma Agamben, se a estrutura do Estado-Nação é definida pelo triplo território-ordenamento-nascimento, o campo é o quarto elemento que vem juntar-se a esta tríade. "É significativo que os campos surjam juntamente com as novas leis sobre cidadania e sobre desnacionalização" (AGAMBEN, 2010a, p. 170-171). "O descolamento crescente entre o nascimento e o Estado-nação é o fato novo da política do nosso tempo, e aquilo que chamamos de campo é seu resíduo" (AGAMBEN, 2010a, p. 171). O mero fato de nascer faz do vivente uma vida nua, sem, contudo, qualquer status político, quando a vida nua não é mais inscrita através de regras automáticas de politização da zoé. Agamben (2010a, p. 171) chama a atenção, portanto, para o fato da formação de um corpus de vida nua, isto é, “[...] aquela vida nua que, em proporção crescente, não pode mais ser inscrita no ordenamento [...]", sendo o campo o seu local de destino.

Com tais assertivas, Agamben pode concluir que o estado de exceção permanente, o campo, corresponde a uma localização sem ordenamento. Se o estado de exceção original (estado de exceção temporário) pressupunha a suspensão temporária da lei e constituía-se em um ordenamento sem localização (ilocalizável), o estado de exceção permanente (desejado, o campo) corresponde a uma localização sem ordenamento, uma localização deslocante (AGAMBEN, 2010a). Expondo de uma maneira mais simples: ao se criar o estado de exceção permanente, este se tornou um paradigma e transmutou-se em uma figura espacial ambulante, uma localização deslocante, que pode surgir nos mais variados lugares, sempre que for conveniente. 
Quando Agamben (2010a,) afirma, portanto, que o campo foi o mais absoluto espaço biopolítico jamais realizado, no qual o poder não tem diante de si senão a pura vida sem qualquer mediação, a expressão que deve ser enfatizada é "sem qualquer mediação". Se o campo de concentração realizou a mais absoluta conditio inhumana, mostrando-se como um absoluto espaço biopolítico, foi porque desnudou a relação que submete a vida ao poder soberano, isto é, a vida nua aparecia no campo como aquela inscrita sem qualquer forma de pertencimento ao corpus político. Essa situação-limite demonstrou, enfim, que as identidades jurídico-políticas, tais como o cidadão, perderam qualquer sentido, ou melhor, repousam, em última instância, sobre o solo podre da vida nua. $\mathrm{O}$ que a exceção permanente põe manifesta é "[...] uma indeterminação da indeterminação profundamente não-relacional, na qual nem o político e muito menos o jurídico podem agir" (MATOS, 2012, p. 332).

No estado de exceção permanente não há política, mas apenas biopolítica. A experiência biopolítica somente é possível justamente por uma vida poder ser isolada de sua forma (identidades jurídico-políticas), indicando que a política moderna não tem fundamento no ser, mas na vida nua que a própria (bio)política outorga ao vivente.

O exemplo do campo como absoluto espaço da biopolítico encontra-se precisamente no muçulmano. Levi (1988) explica que a palavra "muçulmano" - muselmann - era utilizada pelos prisioneiros veteranos do campo de concentração em Auschwitz para designar os ineptos e destinados a serem selecionados para a câmara de gás. Muçulmano não era quem cultuava a fé islâmica, e sim o prisioneiro exaurido que estava prestes a perecer.

Muselmann remete ao termo árabe muslim, aquele que se submete incondicionalmente à vontade de Deus e, talvez ironicamente, o muçulmano do campo de concentração tenha sido assim denominado justamente por ter se entregado ao destino por pura exaustão, sem qualquer vontade, sem qualquer consciência (AGAMBEN, 2010b).

Ser denominado de muçulmano significava, portanto, se encontrar em uma zona entre a vida e a morte, num perpétuo estado de execução. Primo Levi percebeu bem a situação, ao dizer que se hesitava “[...] em 
chamá-los de vivos; hesita-se em chamar de 'morte' à sua morte, que eles já nem temem, porque estão esgotados demais para poder compreendê-la" (LEVI, 1988, p. 91).

Tornar-se muçulmano era uma questão de tempo. Mais uma vez, Primo Levi desperta o leitor para o seguinte fato: "Desejaríamos chamar a atenção sobre o fato de que o campo foi também (e marcadamente) uma notável experiência biológica e social" (LEVI, 1988, p. 88). As cesuras biopolíticas do Reich nazista, num processo de aviltamento e degradação, transformavam o não ariano em judeu, o judeu em deportado, o deportado em internado (Häftling) e, no campo, o internado transmutou-se em $m u$ çulmano, como limite último (AGAMBEN, 2010b).

O muçulmano era o "[...] não-homem que se apresentava obstinadamente como homem, e o humano que é impossível dissociar do inumano" (AGAMBEN, 2010b, p. 87). Isso significa que no muçulmano, como limite entre o humano e o inumano, dois poderes se entrecruzavam. $\mathrm{O}$ absoluto do biopoder de fazer viver juntamente com a absoluta generalização do poder soberano de fazer morrer. Nesse ponto, a biopolítica coincide com a tanatopolítica (AGAMBEN, 2010b), a administração da morte, isto é, a produção da morte torna-se o motor da biopolítica.

“Cheios de si próprio até ao bordo, o Völkerkörper alemão não podia viver a não ser evacuando continuamente a sua carne purulenta: talvez por isso um outro médico nazi chamara a Auschwitz anus mundi" (ESPOSITO, 2010, p. 204).

Se a biopolítica consiste na produção de cesuras no domínio biológico de um determinado corpo político (povo) - o estabelecimento de hierarquia entre raças, por exemplo, entre arianos e não arianos -, estas cesuras biopolíticas levam até ao muçulmano, como limite último. No muçulmano, aquele para o qual nem a morte poderia ser chamada de morte, já não há mais a possibilidade de se estabelecerem cesuras biopolíticas, surgindo uma "substância biopolítica absoluta" (AGAMBEN, 2010b, p. 90); a última substância biopolítica isolável no continuum biológico é o muçulmano, aquele que está além de qualquer identidade biopolicamente atribuível. Justamente por isso, Agamben (2010b) entende que o campo foi o mais absoluto dos espaços biopolíticos. 
A ideia de um campo, de um espaço de exceção permanente, corresponde àquela de um volkloser Raum, um espaço sem povo. Um lugar no qual os povos se transformam em população (não cidadãos) e esta em muçulmanos (AGAMBEN, 2010b).

Quando o estado de exceção permanente e materializado (campo) tornar-se uma localização deslocante, um espaço de exceção móvel consistente na criação de um espaço territorial em que a vida nua e norma entram em uma zona de indistinção, então se deve admitir a presença virtual de um " [.... campo toda vez que é criada tal estrutura, independentemente da natureza dos crimes ai cometidos e qualquer que seja a sua denominação ou topografia específica" (AGAMBEN, 2010a, p. 169-170).

Nesse momento, o campo torna-se paradigma de governo e o sistema político não ordena tão somente formas de vida e normas jurídicas em um espaço determinado, mas administra a própria vida nua, entendida agora como aquela que não pode mais ser inscrita no ordenamento jurídico (AGAMBEN, 2010a).

Ao final, as palavras de Walter Benjamin, como muitas delas, se fizeram atuais: a tradição dos oprimidos ensina que o estado de exceção é, na verdade, a regra (BENJAMIN, 2007).

\section{Conclusão}

O campo foi o mais absoluto espaço biopolítico no qual o poder tem diante de si a pura vida, sem qualquer mediação, porque a vida nua se encontrava inscrita nesse espaço de exceção permanente sem mediação de qualquer forma de pertencimento a um corpo político que, na política ocidental, pressupõe a detenção de direitos assegurados pela lei. O estado de exceção permanente realizou um experimento biopolítico que recaiu não mais sobre a zoé politizada ou a vida nua inscrita no corpo político por meio da relação de inclusão exclusiva, mas simplesmente sobre uma vida nua que não pode mais ser inscrita no ordenamento.

As cesuras biopolíticas realizadas no campo levaram à figura última, ao muçulmano, aquele que se encontrava no limiar entre o humano e 
o inumano. Se o campo funciona como uma localização deslocante, móvel, que cria zonas cinzentas em que fato se confunde com norma, o mais conveniente na atualidade não é perguntar se há um Estado de exceção, mas identificar, nas democracias modernas, os espaços de exceção que, atualmente, tendem à permanência.

\section{Referências}

AGAMBEN, Giorgio. Estado de exceção. Trad. Iraci D. Poleti. 2. ed. São Paulo: Boitempo, 2007.

AGAMBEN, Giorgio. Estado de exceção e genealogia do poder. Revista Brasileira de Estudos Políticos, [S.1.], v. 108, p. 23-39, jan.-jul. 2014. Disponível em: <http://dx.doi.org/10.9732/P.0034-7191.2014v108p21>. Acesso em: 16 jul. 2014.

AGAMBEN, Giorgio. Homo sacer: o poder soberano e a vida nua I. 2 ed. Trad. Henrique Burigo. Belo Horizonte: UFMG, 2010a.

AGAMBEN, Giorgio. Means without end: notes on politics. Trad. Vincenzo Binetti e Cesare Casarino. Minnesota: University of Minnesota, 2000.

AGAMBEN, Giorgio. O que resta de Auschwitz: o arquivo e a testemunha. Trad. Selvino J. Assmann. São Paulo: Boitempo, $2010 \mathrm{~b}$. AGAMBEN, Giorgio. O Reino e a glória: uma genealogia teológica do governo e da economia. Trad. Selvino J. Assmann. São Paulo: Boitempo, 2011.

BENJAMIN, Walter. Über den Begriff der Geschichte. In: BENJAMIN, Walter. Erzählen: Schriften zur Theorie der Narration und zur literarischen Prosa. Frankfurt am Main: Suhrkamp, 2007. p. 129-140.

BENJAMIN, Walter. Zur Kritik der Gewalt. In: BENJAMIN, Walter. Gesammelte Schriften. Vol. II.1. Frankfurt a.M: Suhrkamp, 1999. p. 179-204.

BERCOVICI, Gilberto. Soberania e constituição: para uma crítica do constitucionalismo. São Paulo: Quartier Latin, 2008. 
COCO, Giuseppe. MundoBraz: o devir-mundo do Brasil e o devir-Brasil do mundo. Rio de Janeiro: Record, 2009.

ESPOSITO, Roberto. Bios: biopolítica e filosofia. Trad. M. Freitas da Costa. Lisboa: Edições 70, 2010.

FERREIRA, Bernardo. O risco do político: crítica ao liberalismo e teoria política no pensamento de Carl Schmitt. Belo Horizonte: UFMG, 2004.

FOUCAULT, Michel. Em defesa da sociedade: curso no Collège de France (1975-1976). Trad. Maria Ermantina Galvão. São Paulo: Martins Fontes, 2005.

FOUCAULT, Michel. História da sexualidade I: a vontade de saber. Trad. Maria Thereza da Costa Albuquerque; J. A. Guilhon de Albuquerque. 13. ed. Rio de Janeiro: Graal, 1999.

FOUCAULT, Michel. Segurança, território, população: curso no Collège de France (1977-1978). Trad. Eduardo Brandão. São Paulo: Martins Fontes, 2008.

LEVI, Primo. É isto um homem? Trad. Luigi Del Re. Rio de Janeiro: Rocco, 1988.

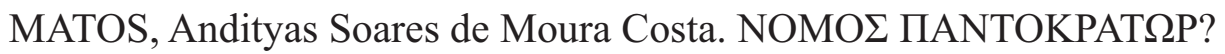
Apocalipse, exceção, violência. Revista Brasileira de Estudos Políticos, [S.1.], v. 105, p. 277-342, jul.-dez, 2012. Disponível em: $<$ http://dx.doi. org/10.9732/P.0034-7191.2012v105p277>. Acesso em: 10 jun. 2014.

PASOLINI, Pier Paolo. Il coito, l'aborto, la falsa tolleranza del potere, il conformismo dei progressisti. In: PASOLINI, Pier Paolo. Scritti corsari. 5. reimp. Milão: Garzantia, 2012. p. 98-109.

SCHMITT, Carl. Legality and legitimacy. Trad. Jeffrey Seitzer.

Durham: Duke university, 2004a.

SCHMITT, Carl. Politische Theologie: Vier Kapitel zur Lehre von der Souveränität. 8. ed. Berlim: Duncker \& Humblot, 2004b.

SCHMITT, Carl. The concept of the political. Trad. George Schwab, Chicago: University of Chicago, 1996. 
Lucas Moraes Martins é professor nos cursos de Direito do Centro Universitário UNA(MG) e da Universidade FUMEC (MG); doutor em Direito pela Universidade Federal de Minas Gerais.

E-mail: lucasmoraesmartins@hotmail.com.

Endereço profissional: Universidade FUMEC - Faculdade de Ciências Humanas, Rua Cobre, n. 200, Cruzeiro, Belo Horizonte, MG - 30310190. 